\title{
RANCANG BANGUN SISTEM INFORMASI MODUL PEMBELAJARAN BERBASIS WEB PADA SMA NEGERI 2 KOTA TANGERANG
}

\author{
Erna Astriyani ${ }^{1}$ \\ Ajay Supriadi ${ }^{2}$ \\ Chesta Mayestica Priyadi ${ }^{3}$ \\ Dosen STMIK Raharja ${ }^{1,2}$ \\ STMIK Raharja Jurusan Sistem Informasi ${ }^{3}$ \\ Jl. Jendral Sudirman No.40, Modern Cikokol Tangerang ${ }^{1,2^{3}}$ \\ Email : erna.astriyani@ raharja.info, ${ }^{1}$ ajay.supriadi@raharja.info ${ }^{2}$,chesta@ raharja.info ${ }^{3}$
}

\begin{abstract}
ABSTRAK
Penggunaan sistem komputer pada dunia pendidikan bukan hal yang asing lagi, karena dalam dunia pendidikan komputer merupakan alat atau akses yang sangat penting dalam menunjang majunya dunia pendidikan. Sistem pembelajaran pada SMA Negeri 2 Kota Tangerang saat ini masih sangat bergantung dengan kehadiran guru di dalam kelas, dan belum terkomputerisasi sehingga jika guru tidak hadir dalam proses pembelajaran maka siswa tidak mendapatkan materi. Dengan adanya permasalahan tersebut maka penulis merancang Modul pembelajaran berbasis web guna mempermudah guru untuk memberikan materi dan memudahkan siswa untuk mendapatkan materi bahan ajar dengan mengakses modul berbasis web yang dapat diakses dimana saja dan kapan saja. Metodelogi yang digunakan dalam penelitian ini yaitu metode observasi, wawancara dan studi pustaka. Untuk metode analisa menggunakan analisa SWOT. Untuk merumuskan perancangan modul berbasis web dimungkinkan dengan menggunakan metode Analisis Sistem, yaitu Elisitasi dan Metode Perancangan yaitu UML (Unified Modeling language) dengan software visual paradigm, menggunakan software XAMPP dengan bahasa pemrograman PHP, serta database menggunakan MySQL. Hasil penelitian ini diharapkan dapat meningkatkan kegiatan belajar mengajar dan dapat mempermudah guru dalam mengupload materi bahan ajar serta memudahkan siswa dalam mendapatkan materi bahan ajar dimana saja dan kapan saja
\end{abstract}

Kata Kunci : XAMPP, UML, Perancangan, Modul, Online, Guru, Siswa

\begin{abstract}
The use of computer systems in education is not something more than that, because in the world of computer education is a very helpful tool in world education. The learning system at SMA Negeri 2 Kota Tangerangis currently very closely related to the teachers in the classroom, and not yet computerized if the teacher is not present in the learning process. With that, you can use the modules used to help teachers to deliver materials and help students to acquire materials using modules that can be accessed anywhere and anytime. Methodology used in this research, ie measurement, interview and literature study. For analysis method use SWOT analysis. To formulate a web-based module is possible by using the System Analysis method, namely Elisitasi and Designing Method that is UML (Unified Modeling language) with visual paradigm software, using XAMPP software with PHP programming language, and database using MySQL. The results of this study are expected to improve teaching and learning activities and can facilitate teachers in uploading teaching materials materials and facilitate students in obtaining teaching materials anywhere and anytime.
\end{abstract}

Keywords: XAMPP, UML, Designer, Module, Online, Teacher, Student 


\section{PENDAHULUAN}

Perkembangan teknologi saat ini sangat pesat termasuk dalam hal sistem informasi yang sangat besar pengaruhnya terhadap dunia pendidikan di Indonesia. Begitu banyak sekolah yang terus berlomba-lomba dalam mengembangkan bidang teknologi dan sistem informasi untuk mempromosikan kualitas sekolah tersebut. Demikian juga diperlukan sarana dan prasarana yang memadai, manajemen yang tepat, pengolahan data yang lebih efektif dan efisien, juga teknologi dan sistem informasi yang dapat mendukung proses kegiatan belajar mengajar.

Pada proses pembelajaran terdahulu, proses belajar mengajar pada umumnya berlangsung diruang kelas dan ditandai dengan kehadiran pendidik didepan kelas, dan pendidik memiliki tanggung jawab penuh terhadap jalannya proses belajar mengajar.

Dalam proses pembelajaran pada SMA Negeri 2 Kota Tangerang, yang berlokasi di Jalan Makam Pahlawan Taruna Tangerang-Banten. Dibutuhkan suatu sistem pembelajaran yang mendukung proses belajar mengajar yang sesuai dengan perkembangan teknologi adalah system pembelajaran $e$-Learning ini menjadikan peserta didik sebagai active learner.

Dalam proses penerapan dan penyelenggaraan e-Learning dibutuhkan sebuah Learning Management System (LMS).Learning Management System (LMS) berfungsi untuk mengatur data laksana penyelenggaraan pembelajaran didalam modeleLearning. Maka pelaksanaan pembelajaran lebih berkualitas karena semua yang diperlukan akan dapat disediakan secara online sehingga dapat diakses kapan saja dengan biaya yang murah dalam penerapan dan penyelenggaraannya. Salah satu Learning Management System yang open source adalah Moodle.

\section{METODE PENELITIAN}

\section{Metode Analisa}

Menurut Kadir (2014 : 416) [1], Analisa SWOT mengandung 4 (empat) bagian :

1. Strengths (S) atau kekuatan

Kekuatan menyatakan karakteristik yang memberi keuntungan untuk organisasi.

2. Weaknesses (W) atau kelemahan

Kelemahan menyatakan karakteristik yang harus di perbaiki supaya memberikan keuntungan bagi organisasi.

3. Opportunities $(\mathrm{O})$ atau peluang

Peluang menyatakan karakteristik yang apabila dimanfaatkan bisa memberikan.

4. Threats $(\mathrm{T})$ atau ancaman

Ancaman menyatakan karakteristik yang memberikan masalah bagi organisasi sehingga perlu dilakukan penanganan untuk mengatasinya.

\section{Metode Pengumpulan Data}

Dalam tahap pengumpulan data untuk penelitian ini, penulis berusaha mengumpulkannya secara bertahap dan data-data yang dikumpulkan adalah data yang relevan dengan judul yang diambil.

Metode Pengamatan (Observasi Research), yaitu dengan mengumpulkan data secara langsung dengan observasi lapangan atau pengamatan terhadap proses pembelajaran. 
Metode Wawancara (Interview Research), metode ini dilakukan dengan cara melakukan tanya jawab dengan beberapa narasumber secara langsung ditempat penelitian berlangsung. Metode ini dilakukan agar data yang di dapatkan lebih detail serta memperkuat data sebelumnya saat melakukan observasi lapangan.

Metode Studi Pustaka (Literature Research), untuk mendapatkan informasi yang terkait dengan permasalahan yang akan diteliti, penulis mengumpulkan data dari berbagai buku, jurnal, serta berbagai laporan guna mendapatkan gambaran secara teoritis dalam pembuatan laporan penelitian ini sebagai acuan.

\section{LITERATURE REVIEW}

Banyak penelitian sebelumnya yang berdasarkan literature review. Oleh karena itu, dalam upaya mengembangkan sistem manajemen aset IT untuk pencatatan history maintenance ini perlu dilakukan studi pustaka sebagai salah satu acuan dalam menerapkan metode penelitian yang akan dilakukan. Beberapa literature review tersebut adalah :

1. Penelitian yang dilakukan oleh Dewi Immaniar Desrisanti, Untung Rahardja dan Rahma Rinie dari perguruan tinggi Raharja (2013) yang berjudul "iLearning Metode Belajar Efektif Untuk Sekolah Tinggi”. Jurnal CCIT. Penelitian ini membahas mengenai tujuan iLearning sebagai metode belajar efektif. iLearning diharapkan dapat menciptakan pembelajaran yang mandiri dan interaktif dalam kehidupan sehari hari dan dapat memecahkan masalah dalam akses pembelajaran.[2]

2. Penelitian yang dilakukan oleh Ary Budi Warsito dan Eka Yuliandari (2017) yang berjudul "Penerapan Google Drive Sebagai Media Penyimpanan Bahan Ajar Perkuliahan Dalam Mendukung Aplikasi Mobile App" Jurnal Sisfotenika Vol.7 No.2. penelitian ini membahas mengenai sistem penyimpanan materi bahan ajar yang ada pada Perguruan Tinggi. Permasalahan yang dihadapi yaitu sistem informasi bahan ajar yang ada pada Perguruan Tinggi saat ini masih menggunakan server sendiri, sehingga biaya yang dikeluarkan akan semakin besar. [3]

3. Penelitian yang dilakukan oleh Tiem Yulianti, Herpratiwi dan Sukirlan (2014) yang berjudul "Pengembangan Bahan Ajar Mandiri Melalui Media Online Untuk Meningkatkan Kemampuan Public Speaking Mahasiswa diPerguruan Tinggi Teknokrat Bandar Lampung" Jurnal Teknologi Komunikasi Pendidikan Vol.2 No.3. membahas 4 (empat) permasalahan, salah satunya membahas materi secara konvensional memerlukan waktu lebih banyak. Setelah dilakukan analisis terhadap usulan untuk pemecahan masalah tersebut yaitu dengan membuat rancangan media online berupa web blog dalam pengelolaan kelas melalui pemanfaatan teknologi pembelajaran mandiri berupa media audio visual untuk materi Public Speaking. [4]

4. Penelitian yang dilakukan oleh M. Mahdian Noor, Nataniel Dengen dan Edy Budiman (2017) yang berjudul "Repository Tugas dan Bahan Ajar menggunakan Layanan Cloud Storage Pada fakultas Ilmu Komputer dan teknologi Informasi". Dalam hal ini terdapat permasalahan dalam hal pendistribusian file bahan ajar maupun tugas dari dosen kepada mahasiswa yang masih menggunakan sistem transfer file menggunakan hardisk maupun flashdisk yang dirasa kurang efektif karena memakan banyak waktu. Sebagai pemecahan masalah yang dihadapi dirancang sebuah sistem repository file yang bersisi bahan ajar dan tugas yang memanfaatkan teknologi cloud computing dengan mengintegrasikan sistem 
repository dengan Cloud Storage sehingga pendistribusian dan manajemen file tugas dan bahan ajar dalam kegiatan perkuliahan bisa lebih efektif dan efisien.[5]

5. Penelitian yang dilakukan oleh Henderi, Muhamad Yusuf, dan Yulika Ayu Rantama pada Perguruan Tinggi Raharja (2012) dengan judul "Penggunaan Metode iLearning Untuk Meningkatkan Kualitas Pembelajaran Di Perguruan Tinggi” Jurnal CCIT. Penelitian ini menjelaskan bahwa salah satu masalah yang sering dihadapi perguruan tinggi saat ini adalah masih kurangnya sistem pembelajaran yang dapat mendukung kualitas belajar mengajar yang baik dan efisien. Saat ini masih menerapkan metode pembelajaran konvensional. Sehingga diciptakanlah metode pembelajaran iLearning dengan sistem terpadu yang diterapkan untuk meningkatkan mutu menuju pembelajaran yang berkualitas dan modern agar mampu melahirkan SDM (Sumber Daya Manusia) yang handal dan bisa bersaing dalam era globalisasi yang didominasi high compettion.[6]

\section{PEMECAHAN MASALAH}

Setelah melakukan analisa serta penelitian yang dilakukan dalam proses pembelajaran yang berjalan saat ini ternyata belum adanya media penyimpanan bahan ajar guru yang bisa diakses secara online dimana saja dan kapan saja. Maka tahap selanjutnya yang peneliti lakukan adalah membahas mengenai sistem usulan untuk melakukan pengembangan sistem pembelajaran berbasis web yang bertujuan untuk mempermudahkan guru dalam melakukan upload materi bahan ajar dan mempermudah siswa dalam mengakses materi bahan ajar. Adapun sistem yang diusulkan untuk prosedur yang baru ini yaitu dengan menggunakan UML untuk menggambarkan Use Case Diagram, Activity Diagram, dan Sequence Diagram.

Dalam hal metode penelitian analisa data, menggunakan analisa SWOT. Berdasarkan penelitian yang sudah di lakukan, hasil analisa SWOT sebagai berikut :

\section{Strengh (Kekuatan)}

Guru dapat memberikan materi bahan ajar tanpa harus masuk kelas.Sistem dapat menampilkan materi bahan ajar yang dapat di download. Sistem dapat diakses secara online dimana saja dan kapan saja

2. Weakness (Kelamahan)

Materi masih belum dapat di update. Guru harus didaftarkan terlebih dahulu oleh admin untuk dapat upload materi

3. Opportunities (Peluang)

Tampilan sistem yang user friendly sehingga memudahkan guru dan siswa.Menjadikan media belajar yang lebih interaktif.

4. Threat (Ancaman)

Karena materi bahan ajar bersifat online terdapat kemungkinan untuk dibukaketika ujian berlangsung.Apabila tidak terhubung dengan internet maka user tidak dapat melakukan upload dan download materi. 


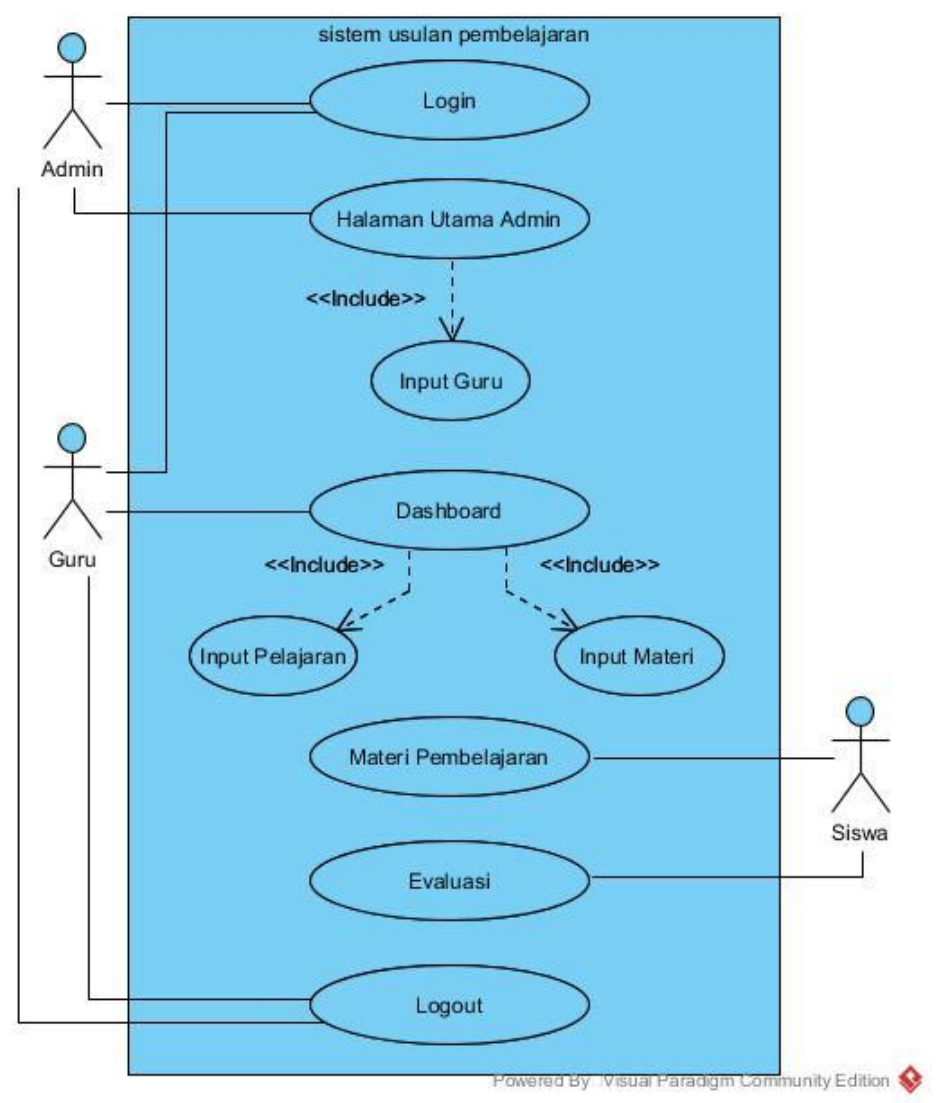

Gambar 1. Use Case Diagram

Pada tampilan di atas (gambar 1), Terdapat 1 (satu) sistem yang mencakup kegiatan sistem pembelajaran.Terdapat 3 (tiga) actor yang melakukan kegiatan didalam sistem yaitu, Admin, Guru, Siswa.Terdapat 6 (enam) Use Case yang dapat dilakukan oleh actor tersebut yaitu, Login, Halaman Utama Admin, Dashboard, Materi Pelajaran, Evaluasi, Logout.Terdapat 3 (tiga) Include yaitu, Input Guru, Input Pelajaran, Input Materi. 


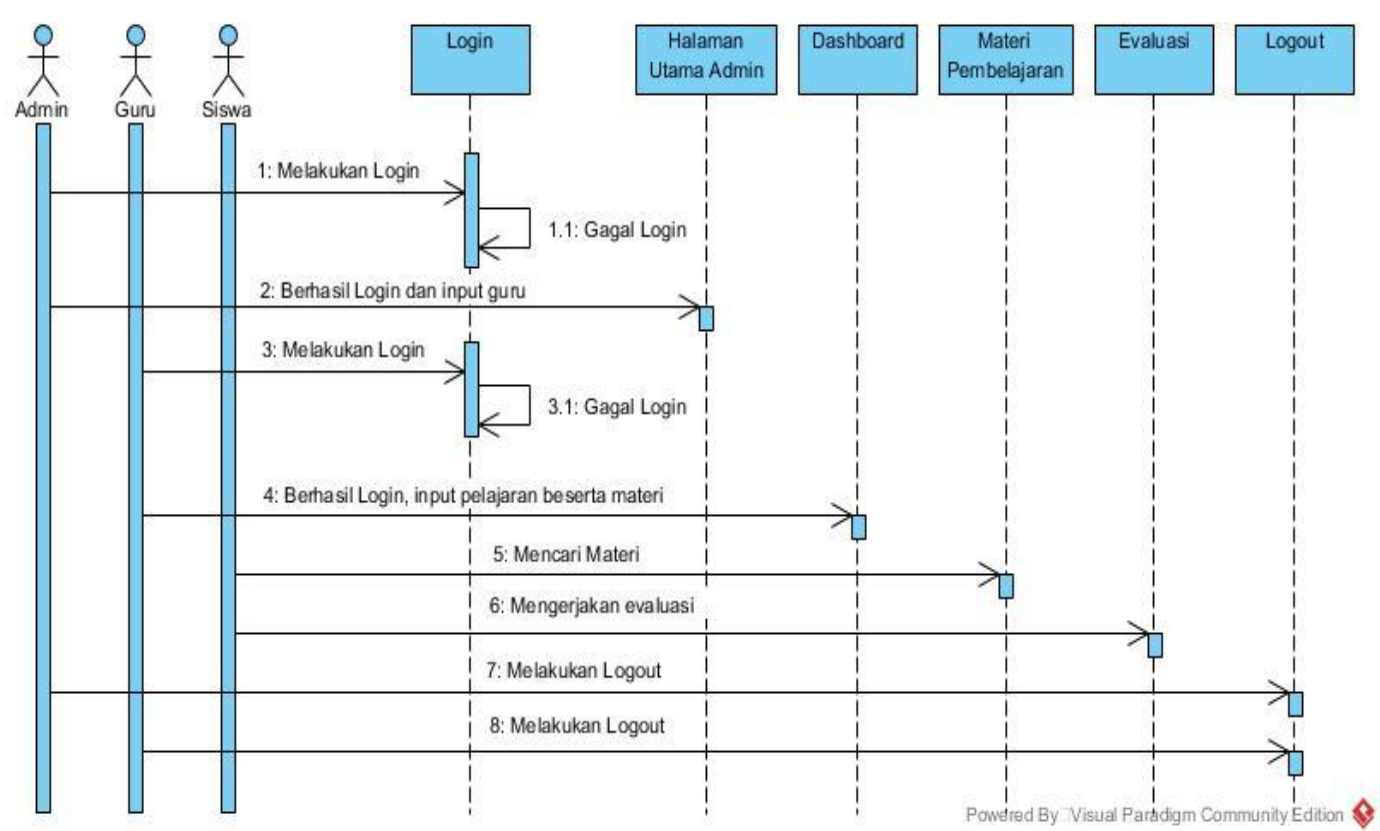

Gambar 2. Sequence Diagram

Pada tampilan di atas (gambar 2), Terdapat 3 (tiga) actor yang melakukan kegiatan yaitu Admin, Guru, Siswa.Terdapat 6 (enam) lifeline yaitu Login, Halaman Utama Admin, Dashboard, Materi Pembelajaran, Evaluasi, Logout.Terdapat 2 (dua) selfmessage yaitu 1.1 gagal login, 3.1 gagal login. Terdapat 8 (delapan) message yang menggambarkan komunikasi, yaitu : melakukan login, berhasil login dan input guru, melakukan login, berhasil login, input pelajaran beserta materi, mencari materi, mengerjakan evaluasi, admin melakukan logout, guru melakukan logout.

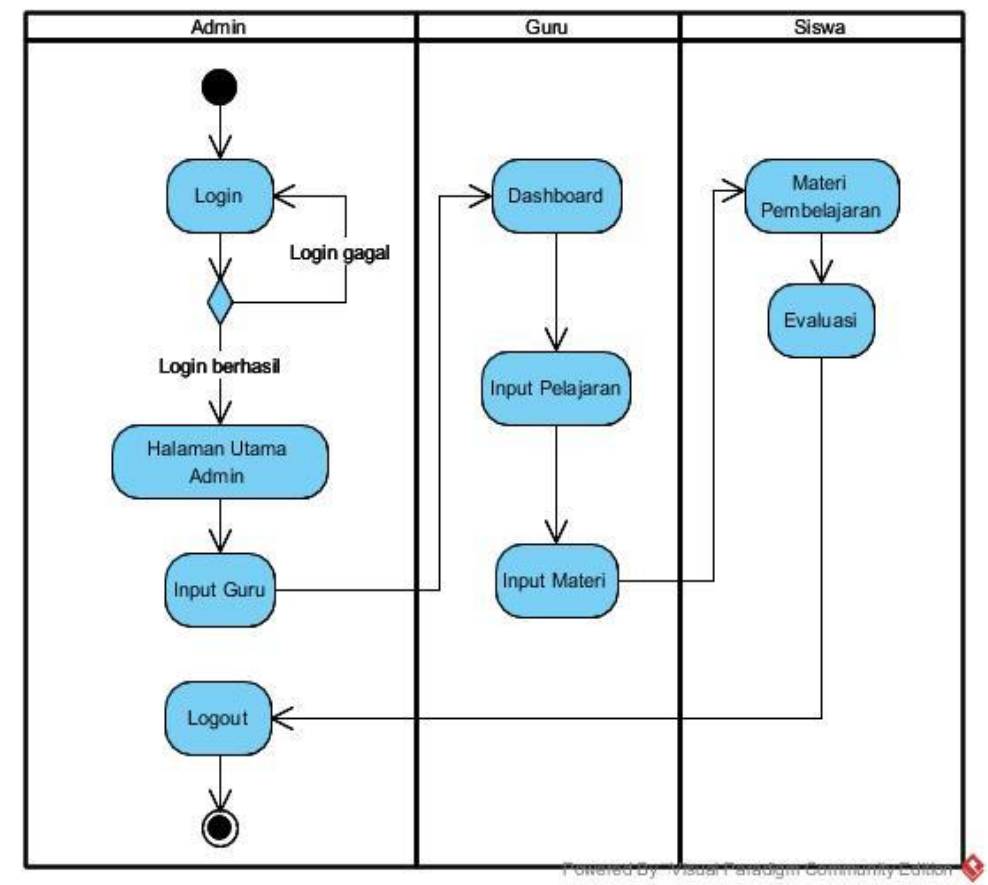

Gambar 3. Activity Diagram 
Pada tampilan di atas (gambar 3),Terdapat 1 (satu) Initial Node, sebagai awal objek. Terdapat 9 (sembilan) action state dari sistem yang mencerminkan eksekusi dari suatu aksi. Login, Halaman Utama Admin, Input Guru, Dashboard, Input Pelajaran, Input Materi, Materi Pembelajaran, Evaluasi, Logout.Terdapat 1 (satu) Final Node, sebagai objek yang diakhiri.

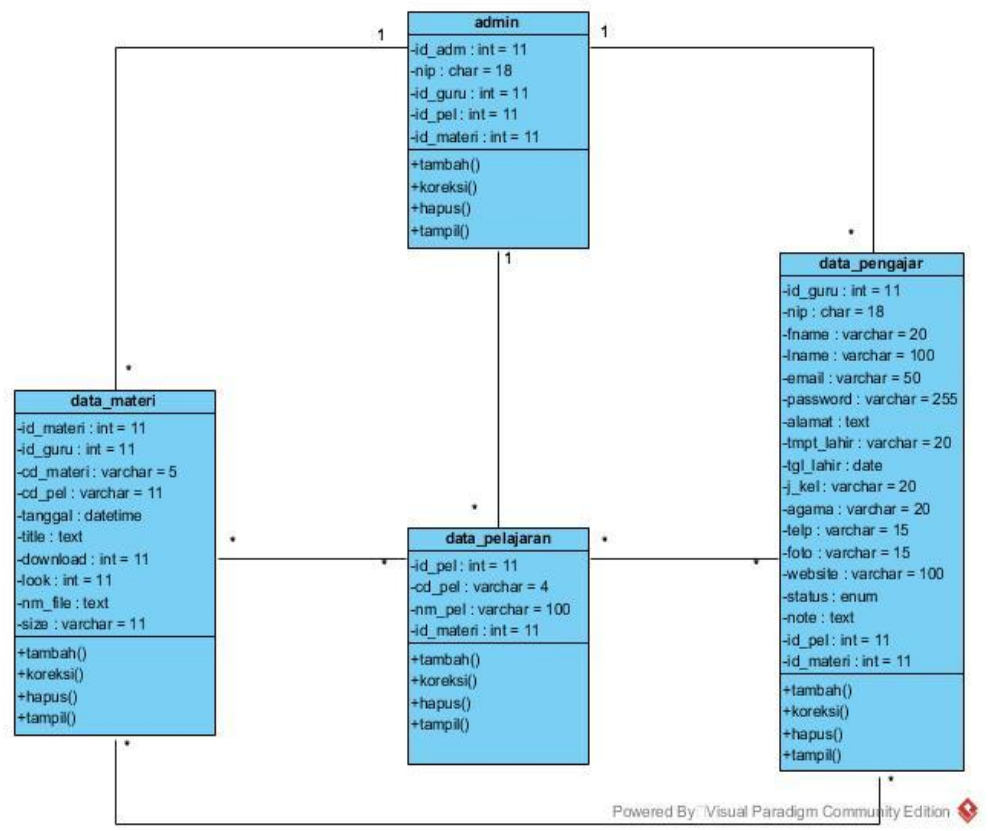

Gambar 4. Class Diagram

Pada tampilan di atas (gambar 4), Terdapat 4 (empat) class, himpunan dari objek-objek yang berbagi atribut serta operasi yang sama, yaitu Class Admin, Class data_pengajar, Class data_pelajaran, Class data_materi.Terdapat 6 (enam) association, digunakan untuk memodelkan relasi di antara objek

\section{IMPLEMENTASI}

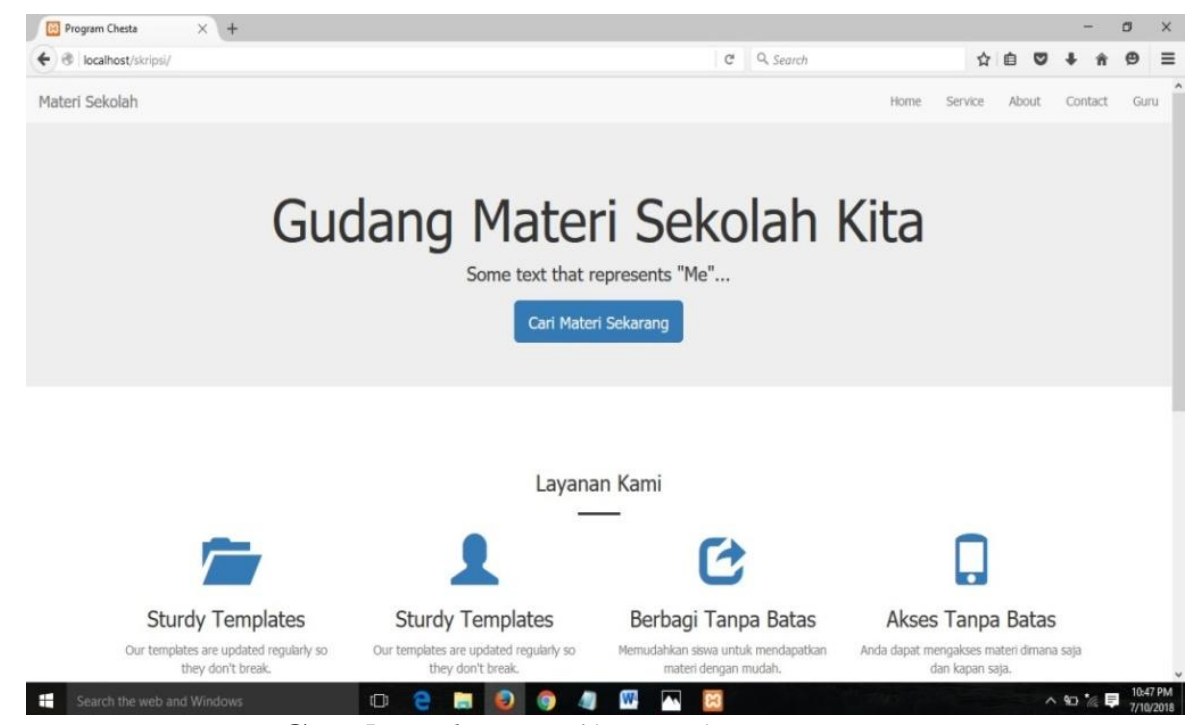

Gambar 6. Tampilan Halaman Utama 
Pada rancangan di atas (gambar 6), merupakan tampilan halamanutama

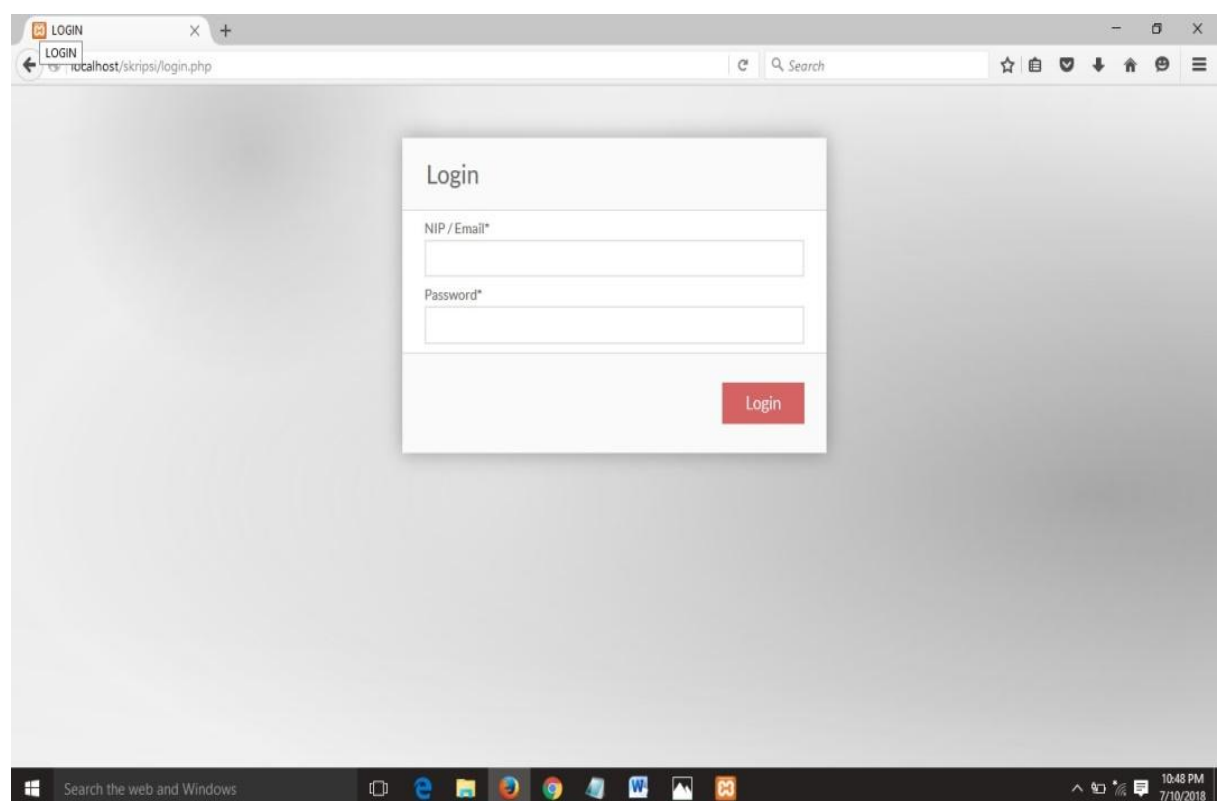

Gambar 7. Tampilan Halaman Login

Pada rancangan di atas (gambar 7), Halaman ini berisi tampilan untuk login admin dan guru. Login dilakukan dengan menggunakan NIP/Email.

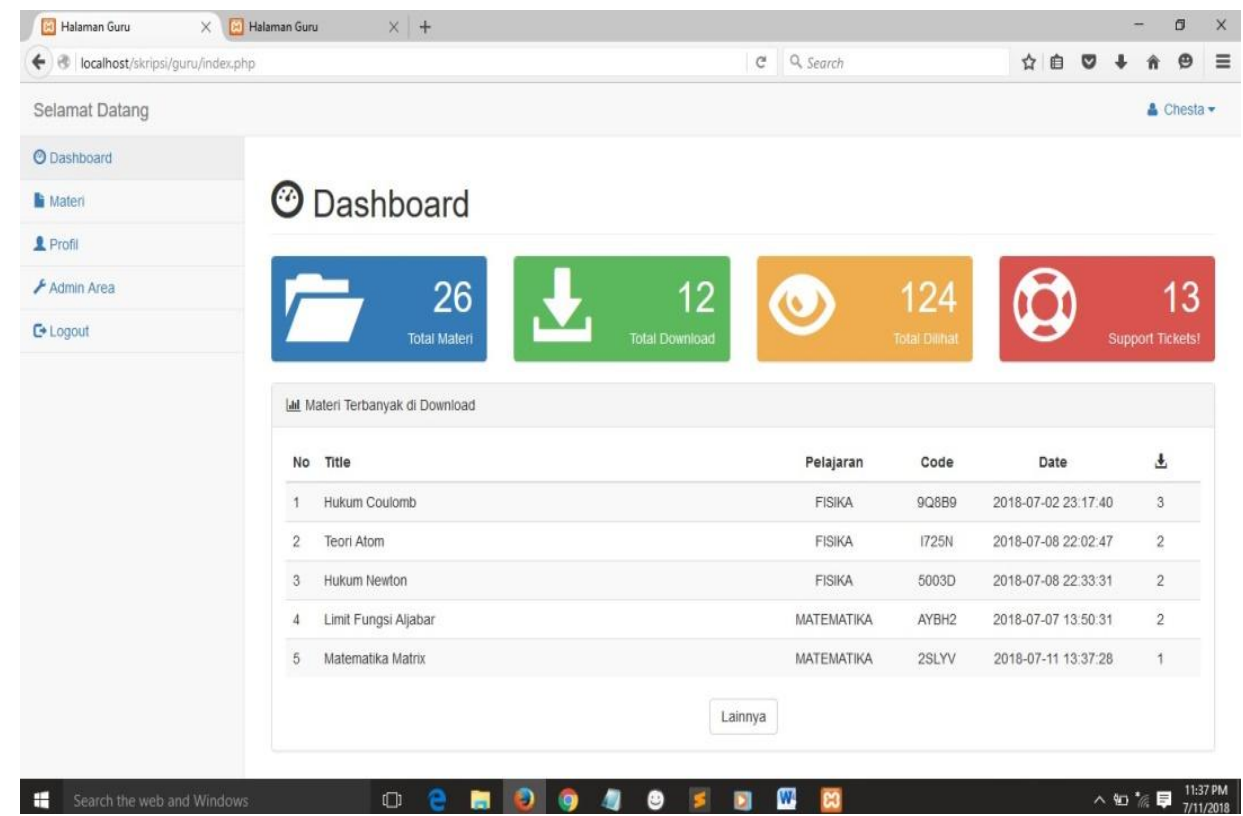

Gambar 8. Tampilan Halaman Utama Admin

Pada rancangan di atas (gambar 8), merupakan tampilan setelah berhasil login dengan memasukan Email dan Password admin bisa masuk ke halaman utama admin atau dashboard, dimana admin dapat melihat daftar nama guru, daftar pelajaran, daftar materi, dll. 


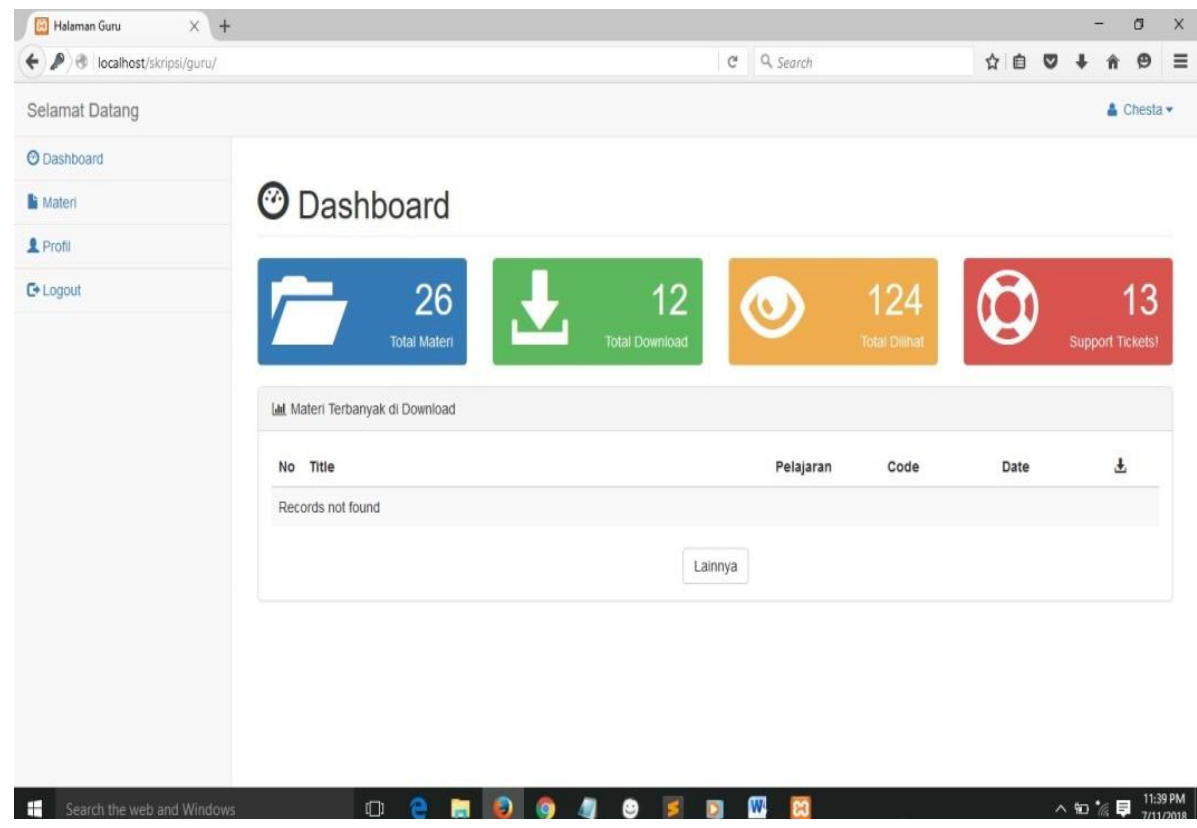

Gambar 9. Tampilan Halaman Utama Guru

Pada rancangan di atas (gambar 8),Setelah berhasil login dengan memasukan Email dan Password guru dapat masuk ke halaman utama guru atau dashboard, dimana guru dapat melakukan upload materi, merubah profile, dll.

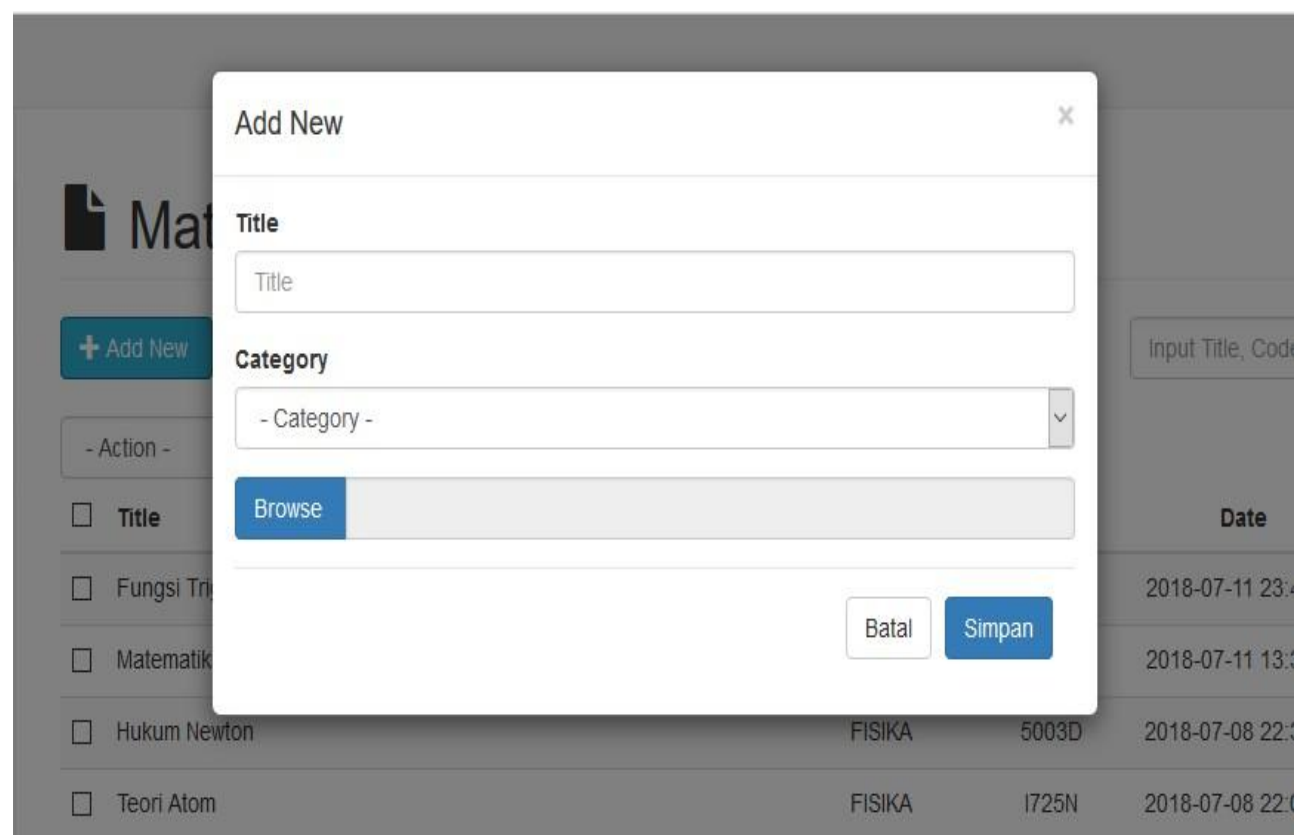

Gambar 10. Tampilan Halaman Upload Materi Guru

Pada rancangan di atas (gambar 10),Di halaman ini terdapat Title, Category, dan Browse untuk guru mengupload materi bahan ajar 


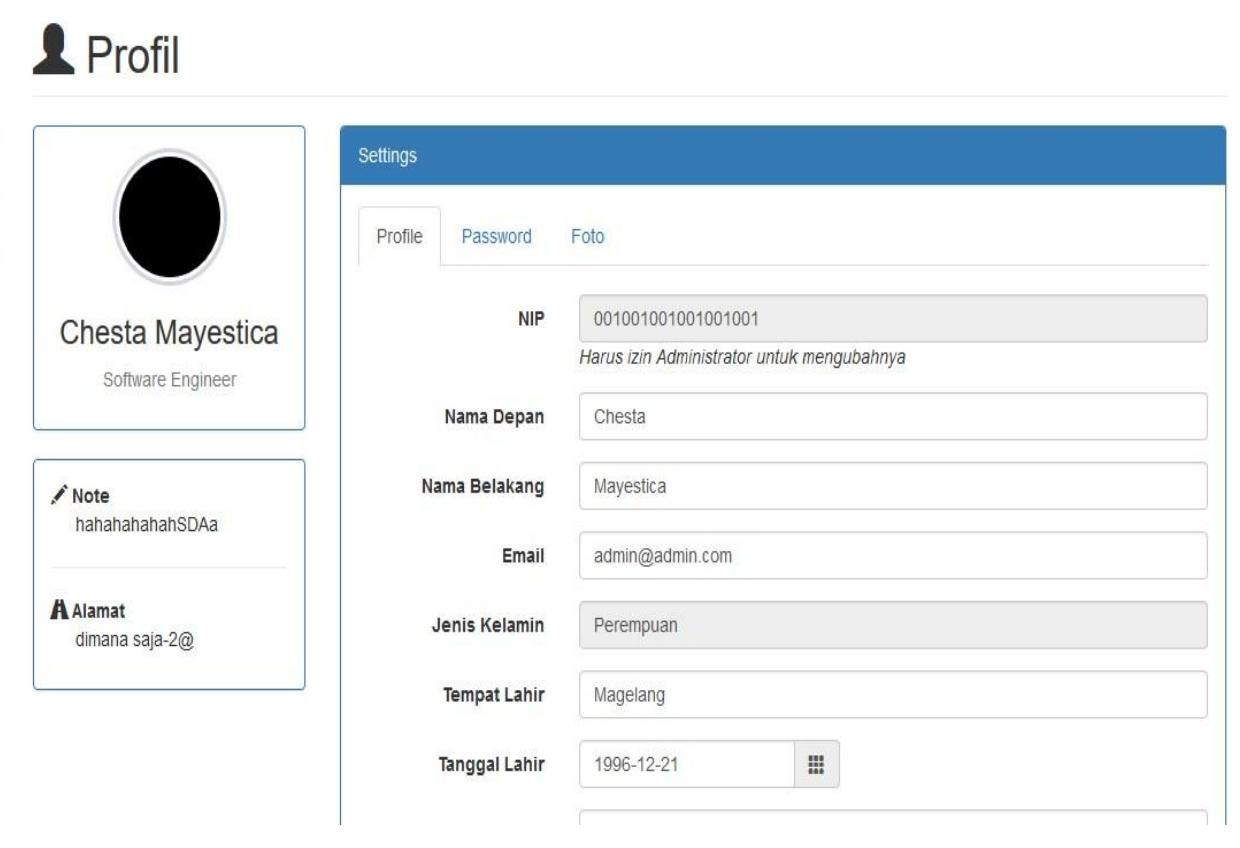

Gambar 11. Tampilan Profil Guru

Pada rancangan di atas (gambar 11), Pada halaman profil guru terdapat NIP, Nama Depan, Nama Belakang,Email, Jenis Kelamin, Tempat Lahir, Tanggal Lahir, Alamat, No.Handphone, Website, Status, Note.

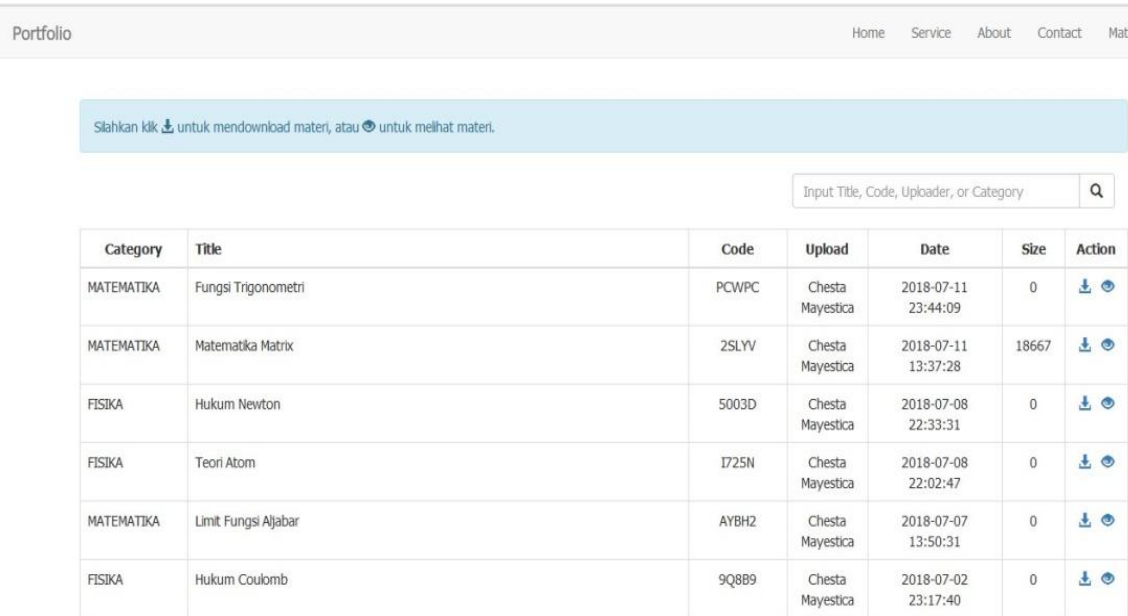

Gambar 12. Tampilan Halaman Materi

pada halaman ini, siswa dapat mendownload materi bahan ajar. Dalam halaman ini terdapat category, title, code, upload, date, size, dan action. 


\section{KESIMPULAN}

Berdasarkan hasil penelitian dari sistem manajemen informasi modul berbasis web, maka penulis dapat menarik kesimpulan sebagai berikut :

Untuk memudahkan siswa dalam mendapatkan materi bahan ajar diperlukanadanya sistem pembelajaran yang terkomputerisasi. Dengan adanya modul berbasis web, tentunya dapat memudahkan guru dalam hal menyediakan materi bahan ajar dan memudahkan siswa dalam mendapatkan materi bahan ajar. Sehingga siswa dapat dengan mudah mendapatkan materi dimana saja, kapan saja, dan langsung terhubung dengan jaringan internet.

\section{DAFTAR PUSTAKA}

[1]. Kadir, Abdul. 2014. Pengenalan Sistem Informasi Edisi Revisi. Yogyakarta: CV. Andi. Offset.

[2]. Desrianti, Dewi Immaniar, Untung Rahardja dan Rahma Rinie. 2013. iLearning Metode Belajar Efektif Untuk Sekolah Tinggi. CCIT Journal. Tangerang: Perguruan Tinggi Raharja.

[3]. Warsito, A. B., \& Yuliandini, E. (2017). Penerapan Google Drive Untuk Efisiensi Penyimpanan Bahan Ajar Yang Dapat Mendukung Sistem Informasi Bahan Ajar Pada Perguruan Tinggi Berbasis Mobile Aplikasi. SISFOTENIKA, 7(2), 219-228.

[4]. Yulianti Tien, Herpratiwi dan Sukirlan . "Pengembangan Bahan Ajar Mandiri Melalui Media Online Untuk Meningkatkan Kemampuan Public Speaking." Jurnal Teknologi Informasi Komunikasi Pendidikan (Old) 2.3 (2015)

[5]. Noor, M. Mahdian, Nataniel Dengen, and Edy Budiman. "Repository Tugas Dan Bahan Ajar Menggunakan Layanan Cloud Storage Pada Fakultas Ilmu Komputer Dan Teknologi Informasi." Prosiding Seminar Ilmu Komputer Dan Teknologi Informasi (Sakti). Vol. 2. No. 1. 2017.

[6]. Henderi, Muhamad Yusuf, dan Yulika Ayu Rantama. 2012. Penggunaan Metode iLearning Untuk Meningkatkan Kualitas Pembelajaran Di Perguruan Tinggi. CCIT Journal. Tangerang: Perguruan Tinggi Raharja. 